\title{
Trends and patterns in total laparoscopic hysterectomy in tertiary care hospital
}

\author{
Sonali Ingole*, Sameer Darawade
}

Department of Obstetrics and Gynecology, SKN Medical College, Pune, Maharashtra, India

Received: 24 April 2018

Accepted: 30 April 2018

\section{*Correspondence:}

Dr. Sonali Ingole,

E-mail: jitendra.ingole@gmail.com

Copyright: (C) the author(s), publisher and licensee Medip Academy. This is an open-access article distributed under the terms of the Creative Commons Attribution Non-Commercial License, which permits unrestricted non-commercial use, distribution, and reproduction in any medium, provided the original work is properly cited.

\begin{abstract}
Background: Due to technical advances in the field of laparoscopy, there has been an increase in total laparoscopic hysterectomies all over the world in last decade. This study was conducted to analyse the technique and surgical outcome of total laparoscopic hysterectomy in tertiary care hospital

Methods: This is a retrospective cohort (observational) study, which included all patients who underwent Total Laparoscopic Hysterectomy (TLH) for benign conditions from January 2012 to December 2017 at the tertiary Care Hospital. The data so obtained was analysed for various parameters like indication for surgery, mean operating time, length of hospital stay, complications and conversion to abdominal route.

Results: Total number of 2307 hysterectomies were performed over a period of 5 years. Of these, TLH were 270 $(11.70 \%)$. Amongst those undergoing TLH, the mean age was $45 \pm 7.84$ years. The most common indication for the surgery was fibroid uterus (38.14\%), followed by dysfunctional uterine bleeding (28.88\%), and adenomyosis (15.1\%). The mean estimated blood loss was $106 \pm 4.34 \mathrm{ml}$. Hemorrhage $(\mathrm{n}=2)$ and bladder injury $(\mathrm{n}=4)$ were most common surgical complications.

Conclusions: TLH is safe and effective procedure for most of the benign pelvic conditions. With adequate training TLH can be used more widely in tertiary care hospital and teaching institute.
\end{abstract}

Keywords: Abdominal hysterectomy, TLH, Vaginal hysterectomy

\section{INTRODUCTION}

Many institutes perform laparoscopic assisted vaginal hysterectomies mainly to improve surgical skills required for laparoscopic surgeries. Adequate training and provision of necessary equipment at a teaching institute can make total laparoscopic hysterectomy as an acceptable approach to hysterectomy. Laparoscopic vaginal hysterectomy was specially advocated to overcome technical difficulties in vaginal hysterectomies, like decreased vaginal capacity, presence of pelvic adhesions or big size of the uterus. However, the vaginal part of LAVH can be still difficult in patients with obesity or nulliparous women with decreased vaginal capacity. ${ }^{1}$

Patients with some degree of prolapse usually are suitable candidates to undergo vaginal and Laparoscopic assisted vaginal hysterectomy. Due to technical advances in this field there has been an increase in total laparoscopic hysterectomies all over the world in last decade. When compared with abdominal hysterectomy (AH) and Laparoscopic assisted vaginal hysterectomy (LAVH), Total Laparoscopic Hysterectomy (TLH) is associated with lesser blood loss, and shorter hospital stay, speedy postoperative recovery. ${ }^{1-5}$ 


\section{METHODS}

This is a Retrospective Cohort (Observational) study done in Department of Obstetrics and Gynaecology at Tertiary Care Hospital (SKN Medical College and General Hospital, Pune). The study was approved by Institutional Ethical committee. This study included the patients who underwent Total Laparoscopic Hysterectomy (TLH) for benign conditions from January 2012 to December 2017, over a period of 5 years. The detailed data was obtained for TLH cases from records maintained in operation theatre registers and medical record section of hospital using ICD-9 coding system. Admission files and operative sheets of patients were also reviewed.

Variables studied included: age, parity, body mass index (BMI), indications for surgery, size of the uterus in weeks, operating time, estimated blood loss and length of hospital stay. Intraoperative complications were categorized as bladder injury, bowel injury, ureter injury and Hemorrhage. Postoperative complications included fever, urinary tract infection, vault hematoma. Other variables were pre and postoperative hemoglobin levels. Number of cases completed successfully, readmission rates, as well as number of cases converted to abdominal hysterectomy were also noted. Readmission was defined as admission to hospital with a diagnosis that was related to surgery. Postoperative infections were defined as those that occurred within 30 days of surgery. All data was analyzed using statistical software.

\section{Summary of technique of TLH}

Patients were admitted from Gynaecology OPD 2 days prior to surgery, after doing necessary preoperative workup including blood investigations, control of blood pressure and stabilization of blood glucose. Informed consent was taken on the prior day of Surgery. Patients were kept NBM for 8 hours prior to surgery. They were advised to take light breakfast the previous day in morning and liquid diet in evening. All patients received enema 12 hours prior to surgery. Intravenous Antibiotic was given 1 hour prior to surgery. All cases were performed under Spinal and General Anaesthesia.

Foleys catheterization was done after painting and draping of abdomen. Carbon-dioxide insufflation was done using $10 \mathrm{~mm}$ supraumbilical port created by umbilical tube technique (open technique). Intraperitoneal pressure was kept up to $12 \mathrm{mmHg}$ throughout surgery. Two $5 \mathrm{~mm}$ ports were placed lateral to umbilicus in midclavicular line. Other two ancilliary ports were placed in right and left iliac fossa. Patients were placed in Trendelenburg position after placement of primary port, during the surgery. Manipulation of the uterus was done using uterine manipulator. Round ligament, tubo-ovarian ligaments were coagulated using bipolar and cut with scissors on both sides. Posterior peritoneum was dissected using bipolar and scissor, above the level of attachment of uterosacral ligament. Uterovescical peritoneal fold was opened from left side and then continued upto right round ligament and bladder was separated by scissors, from underlying cervix and vagina. Bilateral uterine arteries were coagulated with bipolar and lateralized with Scissors. Mangeshikar uterine manipulator was then introduced from below which delineated the vaginal cuff, and vault was opened using monopolar hook with cutting current. Specimen was removed vaginally. Infundibulo-pelvic ligament was desiccated and cut similarly in patients who required oophorectomy. Endosuturing of the vault was done using suture Polyglactin no 1.

\section{RESULTS}

Total number of 2307 hysterectomies were performed over a period of 5 years (Table 1). Majority of hysterectomies were abdominal hysterectomies 929 $(40.2 \%)$. Other hysterectomies data is as under, vaginal hysterectomies: 901 (39.05\%), LAVH 90 (3.90\%), TLH $270(11.70 \%)$ and radical hysterectomies were (5.07\%).

Table 1: Annual number of hysterectomies in $\mathbf{5}$ years.

\begin{tabular}{|llllll|}
\hline $\begin{array}{l}\text { Hysterectomy } \\
\text { Technique }\end{array}$ & Year & Year & Year & Year & Year \\
\hline Abdominal & 186 & 2014 & 2015 & 2016 & 2017 \\
\hline Vaginal & 158 & 138 & 238 & 158 & 143 \\
\hline LAVH & 32 & 27 & 16 & 225 & 156 \\
\hline TLH & 13 & 32 & 38 & 70 & 2 \\
\hline $\begin{array}{l}\text { Radical } \\
\text { hysterectomy }\end{array}$ & 12 & 27 & 29 & 32 & 17 \\
\hline
\end{tabular}

Of the 270 women who underwent TLH during the study period, the mean age of patients was $45 \pm 7.84$ years (Table 2). The mean parity was $2.64 \pm 1.26$ and four were nulliparous women $(1.48 \%)$.

Number of women with postmenopausal status were 26 $(9.62 \%)$. Women with one or more previous cesarean section were six $(2.22 \%)$.

Table 2: Demographic characteristics in patients of TLH.

\begin{tabular}{|l|l|}
\hline Variables & Mean value \pm SID \\
\hline Age (in years) & $45 \pm 7.84$ \\
\hline Parity & $2.64 \pm 1.26$ \\
\hline Operating time (in min) & $146 \pm 25.54$ \\
\hline Average BMI & $28.4 \pm 5.86$ \\
\hline Average blood loss (mL) & $106 \pm 43.23$ \\
\hline Preoperative hemoglobin $(\mathrm{gm} / \mathrm{dL})$ & $10.87 \pm 1.38$ \\
\hline Postoperative hemoglobin $(\mathrm{gm} / \mathrm{dL})$ & $10.56 \pm 1.07$ \\
\hline Duration of hospital stay (days) & $3.12 \pm 1.34$ \\
\hline Size of the uterus (weeks) & $10.65 \pm 4.34$ \\
\hline
\end{tabular}

The Indications for TLH are shown in Table 3. The most common indication for the surgery was fibroid uterus 
(38.14\%), followed by dysfunctional uterine bleeding $(28.88 \%)$, and adenomyosis $(15.1 \%)$.

Table 3: Indications for TLH.

\begin{tabular}{|ll|}
\hline Indications & $\begin{array}{l}\text { No. of patients } \\
\text { (percentage) }\end{array}$ \\
\hline Fibroid uterus & $103(38.14)$ \\
\hline Dysfunctional uterine bleeding & $78(28.88)$ \\
\hline Adenomyosis & $41(15.1)$ \\
\hline Recurrent Postmenopausal bleeding & $7(2.59)$ \\
\hline Benign ovarian tumours & $13(4.81)$ \\
\hline Atypical endometrial hyperplasia & $4(1.48)$ \\
\hline Chronic PID & $17(6.29)$ \\
\hline Cervical intraepithelial neoplasia & $7(2.59)$ \\
\hline
\end{tabular}

The operating time was calculated as start of first incision on the skin upto skin closure of last port. Mean operating time $146 \pm 25.54$ minutes.

The mean uterine size was $10.65 \pm 4.34$ weeks. The largest size of the uterus was 16 weeks and the range was from normal size to 16 weeks. Blood loss was calculated by measuring the blood in suction canister excluding the fluid used for irrigation and suction intraoperatively. The mean estimated blood loss was $106 \pm 43.23 \mathrm{ml}$.

The postoperative hemoglobin levels as measured on postoperative day 1 was more than $9 \mathrm{gm} \%$ for all the patients. One patient required intraoperative blood transfusion while none of the patients required postoperative blood transfusion. Eight patients were given intravenous iron preparation postoperatively.

\section{Postoperative Complications}

A total of 270 patients underwent attempted TLH, out of which, the procedure was successfully completed in 259 patients $(95.92 \%)$.

Seven patients were converted to laparotomy secondary to intraoperative complications $(2.5 \%)$. These included, one case of bowel injury (mid ileal injury), two patients had intraoperative bleeding which required conversion to abdominal route.

Table 4: Operative complications.

\begin{tabular}{|l|l|}
\hline Major complications & No. \\
\hline Hemorrhage & 2 \\
\hline Injury to bladder & 4 \\
\hline Injury to bowel & 1 \\
\hline Injury to ureter & 1 \\
\hline DVT & 1 \\
\hline Minor complications & \\
\hline Fever & 9 \\
\hline Urinary tract infection & 6 \\
\hline Vault hematoma & 0 \\
\hline Vault abscess & 0 \\
\hline
\end{tabular}

There were four cases of bladder injury (Table 4) for which laparoscopic surgery was abandoned and hysterectomy with subsequent bladder repair was completed by opening the abdomen. Out of four cases of bladder injury, one patient had history of previous cesarean section.

Two patients had dense adhesions and hence were converted to open surgery before any significant laparoscopic dissection was done. The mean duration of hospital stay was $3.12 \pm 1.34$ days (from the day of operation).

Repeat laparotomy was required in two patients. One patient had ureteric injury (ureterovaginal fistula) and the other developed VVF (Vesico-Vaginal Fistula) after primary bladder repair. Same patient also developed deep vein thrombosis, where prolonged operative time (5.5 hours) was considered as a possible risk factor for development of DVT.

Minor postoperative complications like fever were found in twelve patients, and urinary tract infection in six patients while none of the patients had vault abscess or vault hematoma.

\section{DISCUSSION}

Hysterectomy is the most commonly performed Gynaecological surgery. Laparotomy is the standard method of hysterectomy. Many surgeons are accepting laparoscopic hysterectomy as an alternative to standard abdominal hysterectomy. Authors have reported variety of techniques for performing this procedure. Less postoperative discomfort, less chance of postoperative wound dehiscence and quick return to daily activities and shorter duration of hospital stay are advantages of TLH. Shorter hospital stay prevents the risk of nosocomial infection.

Many randomized trials have shown this advantage of laparoscopic hysterectomy over abdominal. ${ }^{7}$ This study reports the surgical outcome of 270 patients with TLH. Our data is similar to those reported elsewhere with respect to patient demographics, operation time and operative morbidity. 8,9 TLH can also be performed in obese patients and operating time in such patients is comparable to the time required in abdominal route. ${ }^{10-12}$ Our study found no difference in surgical outcomes in obese patients as compared to those with normal BMI.

Preservation of uterosacral ligament helps in maintaining vaginal innervations. Also laparoscopic vault closure decreases risk of granuloma formation. The complications occurring in TLH and patient safety have been a major concern in past. Liu and Reich reviewed 518 patients undergoing TLH. ${ }^{13}$ They found that the risk of TLH is no greater than either abdominal hysterectomy or vaginal hysterectomy in appropriately trained hands. Urological complications occurred in $1.85 \%$ of patients. 
Reoperation was required in 2 patients $(0.74 \%)$. Conversion rate due to dense adhesions was $0.74 \%$ in the present study.

Patients with TLH experience less pain and require less postoperative analgesia as compared to Abdominal Hysterectomy. Though some studies have mentioned longer operating time and longer anaesthesia, TLH is associated with shorter stay and early recovery from the surgery as compared to $\mathrm{AH} .{ }^{14}$ Also, TLH has very minimal risk of postoperative adhesions and less chances of wound dehiscence. Because TLH does not depend on parity and vaginal laxity unlike vaginal hysterectomy, this minimally invasive surgery can be offered to more women including nulliparous and obese women.

Performing TLH involves a learning curve, and a period of training necessary to standardize the procedure, will result in safer procedure and improved outcomes. Surgical outcome in TLH depends on number of factors mainly surgeon expertise, assisting staff, and surgical instruments. Laparoscopic surgeries at postgraduate level in teaching hospital will allay the anxiety in beginners. Ongoing review of performance and surgical outcome of the procedure will help in improved results related to the procedure.

\section{CONCLUSION}

TLH is safe and effective procedure for most of the benign pelvic conditions. With adequate training TLH can be used more widely in tertiary care hospital and teaching institute where resident doctors can be trained gradually. With availability of technical support, more number of laparoscopic surgeries will be possible at teaching institutions.

Funding: No funding sources

Conflict of interest: None declared

Ethical approval: The study was approved by the Institutional Ethics Committee

\section{REFERENCES}

1. Johnson N, Barlow D, Lethaby A, Tavender E, Curr L, Garry R. Methods of hysterectomy: systematic review and meta-analysis of randomized controlled trials. BMJ. 2005;330(7506):1478.

2. Long CY, Fang JH, Chen WC, Su JH, Hsu SC. Comparison of total laparoscopic hysterectomy and laparoscopic assisted vaginal hysterectomy. Gynecol Obstet Invest. 2002;53:214-9.

3. Harry R, Lisa R. Laparoscopic hysterectomy in current gynecological practice. Gynocol Perinatal Prac. 2003;3:32-40.

4. Sutton C. Hysterectomy: a historical perspective. Baillieres Clin Obstet Gynaecol. 1997;11(1):1-22.

5. Wood C, Maher PJ. Laparoscopic hysterectomy. Baillieres Clin Obstet Gynaecol. 1997;11(1):111-36.

6. Thiel J, Gamelin A. Outpatient total laparoscopic hysterectomy. J Am Assoc Gynecol Laparosc. 2003;10(4):481-3.

7. Chapron C, Dubuisson JB, Ansquer Y. Total laparoscopic hysterectomy: indications, results, and complications. Ann N Y Acad Sci. 1997;828:341-51.

8. Hawe JA, Garry R. Laparoscopic hysterectomy. Semin Laparosc Surg. 1999;6(2):80-9.

9. Ottosen C, Lingman G, Ottosen L. Three methods for hysterectomy: a randomized, prospective study of short term outcome. BJOG. 2000;107:1380-5.

10. Cheung VYT, Rosenthal DM. Laparoscopic versus abdominal supra cervical hysterectomy. J Am Assoc Gynecol Laparosc. 2002;9:S68.

11. Garry R, Fountain J, Mason S, Napp V, Brown J, Hawe J, et al. The evaluate study: two parallel randomized trials, one comparing laparoscopic with abdominal hysterectomy, the other comparing laparoscopic with vaginal hysterectomy. BMJ. 2004;328:129-36.

12. Cheung VYT, Rosenthal DM. TLH versus LAVH. J Am Assoc Gynecol Laparosc. 2002;9:S8.

13. Liu C, Reich H. Complications of total laparoscopic hysterectomy in 518 cases. Gynaecol Endosc. 1994;3:203-8.

14. Garry R. The future of hysterectomy. BJOG. 2005;112:133-9.

Cite this article as: Ingole S, Darawade S. Trends and patterns in total laparoscopic hysterectomy in tertiary care hospital. Int J Reprod Contracept Obstet Gynecol 2018;7:2170-3. 